\title{
VARIABILIDADE ESPACIAL DO ARMAZENAMENTO E PERDA MÉdiA diÁRIA de ÁGUA PELO SOLO NO SISTEMA DE SEMEADURA DIRETA EM CAMPINAS, SP ( $\left.{ }^{1}\right)$
}

\author{
GLÉCIO MACHADO SIQUEIRA $\left({ }^{2 *}\right)$; SIDNEY ROSA VIEIRA $\left({ }^{3}\right)$; \\ MARCELO BENTO PAES DE CAMARGO $\left(^{3}\right)$
}

\begin{abstract}
RESUMO
O processo de armazenamento de água no solo depende de características internas e externas ao meio. Desta maneira, este estudo teve como objetivo avaliar a variabilidade espacial do armazenamento $(\mathrm{mm})$ e a perda média diária de água pelo solo $\left(\mathrm{mm} \mathrm{dia}^{-1}\right)$ cultivado com mamona (Ricinus cummunis L.), em semeadura direta, e sua relação com os agentes meteorológicos (precipitação, radiação solar, temperatura e direção do vento) em Campinas (SP). As medições de umidade do solo foram efetuadas em 10 de janeiro (método volumétrico), 1. ${ }^{\circ}$ de fevereiro (método gravimétrico), 09 e 11 de maio de 2005 (com TDR) na camada de 0,0-0,1 m, em Latossolo Vermelho eutroférrico em semeadura direta. O armazenamento de água no solo e a perda média diária de água pelo solo indicam similaridade no padrão de variabilidade espacial dos dados para a área de estudo. Na face norte do terreno, ocorreram as maiores perdas de água para o sistema. Não foi possível determinar a magnitude da interferência dos elementos meteorológicos sobre o armazenamento de água no solo para o período de estudo.
\end{abstract}

Palavras-chave: conteúdo de água no solo, relação água-solo-atmosfera, geoestatística.

\section{ABSTRACT \\ SPATIAL VARIABILITY OF WATER STORAGE AND DAILY AVERAGE WATER LOSS ON A CULTIVATED SOIL UNDER NO TILLAGE IN CAMPINAS, SÃO PAULO STATE}

Soil water storage depends on internal and external environmental characteristics. In this way, the objective of this study was to evaluate the storage $(\mathrm{mm})$ and daily average soil water loss ( $\mathrm{mm} \mathrm{day}^{-}$ ${ }^{1}$ ) under no tillage system cultivated with castor oil plant (Ricinus cummunis L.) and the relationship with meteorological variables (precipitation, solar radiation, temperature and wind direction) in Campinas (SP, Brazil). The soil water content measurements were made on 01/10 (volumetric method), 02/01 (gravimetrical method), 05/09 and 05/11/2005 (with TDR) at $0.0-0.1 \mathrm{~m}$ depth, in a Rhodic Eutrudox under no tillage system. The water storage and daily average soil water loss indicate similarity in the spatial variability pattern for the data on the study area. The portion of the area which faces northward showed the largest water losses in the system. It was not possible to determine the magnitude of the effect of meteorological variables on soil water storage for the studied period.

Key words: soil water content, water-soil-atmosphere relations, geostatistics.

${ }^{1}$ ) Parte da Dissertação de Mestrado em Agricultura Tropical e Subtropical (IAC) do primeiro autor. Recebido para publicação em 28 de junho de 2006 e aceito em 29 de agosto de 2007.

$\left({ }^{2}\right)$ Doutorando em Engenharia para o Desenvolvimento Rural, Universidade de Santiago de Compostela (USC), Campus Universitario, 27002 Lugo, Espanha. E-mail: glecio.machado@rai.usc.es. (*) Autor correspondente. Bolsista MAEC-AECI.

$\left(^{3}\right)$ Instituto Agronômico (IAC), Campinas (SP). Caixa Postal 28, 13012-970, Campinas (SP)'. E-mail: sidney@iac.sp.gov.br; mcamargo@iac.sp.gov.br 


\section{INTRODUÇÃO}

O sistema de semeadura direta, além de diminuir consideravelmente o revolvimento do solo, contribui com o aumento da palha em superfície, e age diretamente no comportamento de muitos atributos do solo, entre eles o armazenamento de água (TAVARES Filho et al., 2001; Silva et al., 2006), devido à manutenção da palha em superfície, propiciando o desenvolvimento de um microclima com características distintas ao cultivo convencional.

É preciso compreender a dinâmica da variabilidade espacial e temporal do armazenamento de água no solo em semeadura direta. VIEIRA et al. (1992) e Grego e Vieira (2005), estudando a variabilidade espacial de atributos físico-hídricos do solo descrevem que esses atributos possuem alta variabilidade. GonçALvEs et al. (1999) ressaltam que a caracterização da variabilidade do armazenamento de água no solo é extremamente dependente de uma adequada amostragem.

A variabilidade, tanto espacial como temporal, da disponibilidade hídrica dos solos, é de fundamental importância na quantificação das necessidades hídricas dos vegetais (Alfonsi et al., 1998) e de grande importância para a análise do comportamento de uma cultura, pois são variações de umidade no solo e, conseqüentemente, do armazenamento de água no perfil. É preciso considerar que a variabilidade espacial do armazenamento de água no solo é função direta de sua umidade, que varia espacialmente, no sentido horizontal e em profundidade.

Reichardt e Timm (2004) ponderam que havendo movimento da água no solo, adições por chuva ou irrigação e retiradas por evapotranspiração, esses perfis mudam de forma e, logicamente, o armazenamento é diferente. O fluxo de água no sistema edafo-climático é constante e, por esse motivo, é preciso tomar como referência valores de umidade em função do tempo para a melhor compreensão da variabilidade espacial do conteúdo de água no solo.

O monitoramento da umidade permite a determinação do volume de água contido em determinada camada de solo, auxiliando o manejo da água, do solo e das culturas. Sabe-se que no sistema de semeadura direta a quantidade de água armazenada pelo solo é maior do que no sistema convencional (TAVARES FiLHO et al., 2001), pois, as palhas mantidas em superfície juntamente com o dossel das culturas geram um microclima favorável à manutenção da água no solo, com considerável diminuição das perdas por evaporação (Rosolem et al., 2003). Nesse contexto, também, é preciso considerar a atuação dos elementos meteorológicos sobre o solo em semeadura direta, visando à melhor compreensão da variabilidade espacial do armazenamento e da perda média diária de água pelo solo.

A análise dos elementos meteorológicos (precipitação pluvial, radiação solar, temperatura e direção do vento) que interferem sobre o armazenamento de água no solo, fornece uma gama de informações que favorece a minimização da ação da deficiência hídrica do solo sobre o desenvolvimento das culturas.

Desta maneira, este trabalho teve como objetivo analisar a variabilidade espacial do armazenamento de água $(\mathrm{mm})$ e da perda média diária de água pelo solo $\left(\mathrm{mm} \mathrm{dia}^{-1}\right)$ cultivado com mamona (Ricinus cummunis L.), em semeadura direta, e sua relação com os agentes meteorológicos (precipitação pluvial, radiação solar, temperatura e direção do vento), em Campinas (SP).

\section{MATERIAL E MÉTODOS}

O experimento foi desenvolvido em uma área de 3,42 hectares no Centro Experimental Central do Instituto Agronômico em Campinas (SP). O solo da área é Latossolo Vermelho eutroférrico, com declividade de cerca de $6,5 \%$. As coordenadas geográficas da área são $22^{\circ} 53^{\prime}$ de latitude Sul e $47^{\circ}$ $04^{\prime}$ de longitude Oeste e altitude média de cerca de 670 metros. A área vem sendo cultivada sob o sistema de semeadura direta há mais de vinte anos e no momento das amostragens estava sendo cultivada com mamona (Ricinus communis L.) cultivar IAC Guarani.

O clima, de acordo com a classificação climática de Köppen é Cwa, com uma estação quente e chuvosa de outubro a março, temperatura média entre 22 e $24{ }^{\circ} \mathrm{C}$ e total de chuvas de $1.057 \mathrm{~mm}$; e uma estação mais seca de abril a setembro, com temperatura entre 18 e $22{ }^{\circ} \mathrm{C}$ e $325 \mathrm{~mm}$ de chuva (ORTOLANi et al., 1995). Na figura 1 estão relacionados os totais de precipitação pluvial média para a cidade de Campinas, nos últimos cinco anos.

O monitoramento da umidade do solo foi realizado utilizando diferentes métodos de amostragem em: 10 de janeiro (método volumétrico), $1 .^{\circ}$ de fevereiro (método gravimétrico), 09 e 11 de maio de 2005 (TDR - Reflectrometria de domínio do tempo) na camada de $0,0-0,1 \mathrm{~m}$, em grade regular de $10 \mathrm{x}$ 10 metros em 302 pontos de amostragem (Figura 2). A umidade volumétrica do solo $\left(\mathrm{m} \mathrm{m}^{-3}\right)$ obtida em 10/ $1 / 2005$ foi avaliada utilizando-se anéis volumétricos de $100 \mathrm{~cm}^{3}$ que favoreceram a determinação da massa 
úmida e da massa seca das amostras em estufa a 105 ${ }^{\circ} \mathrm{C}$ e da densidade do solo $\left(\mathrm{kg} \mathrm{dm}^{-3}\right)$, conforme descrito por (CAMARGo et al., 1986). A umidade determinada por meio do método gravimétrico ou de pesagens consiste na retirada de amostras indeformadas de solo e determinação em laboratório do conteúdo de água no solo por meio da diferença entre massa úmida e massa seca (CAMARGO et al., 1986), porém, neste caso, a umidade é dada em $\mathrm{g} \mathrm{g}^{-1}$, sendo necessária sua transformação para umidade em base de volume de solo $\left(\mathrm{m} \mathrm{m}^{-3}\right)$ utilizando-se os valores de densidade do solo obtidos por meio das amostras coletadas no dia 10/01/2005 (CAMARGO et al., 1986).

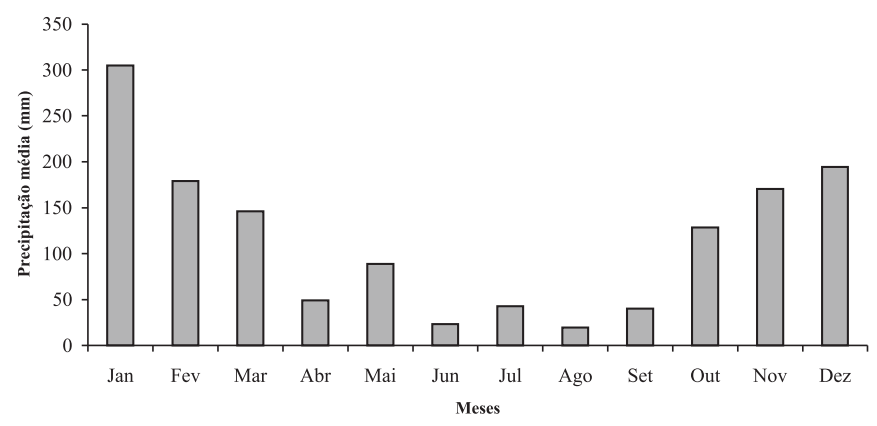

Figura 1. Precipitação pluvial média ao longo do ano para a cidade de Campinas, nos últimos 5 anos.

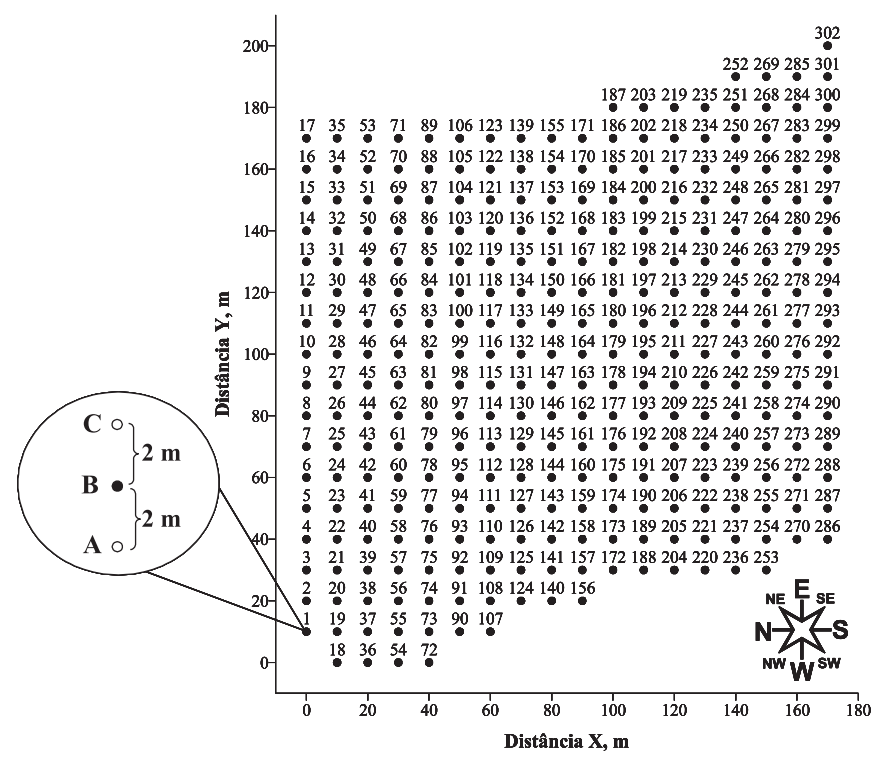

Figura 2. Esquema de coleta de amostras na área de estudo, contendo os 302 pontos de amostragem em grade regular de $10 \times 10$ metros.
A técnica de reflectometria de domínio do tempo (TDR) foi utilizada para determinação do conteúdo volumétrico de água no solo $\left(\mathrm{m} \mathrm{m}^{-3}\right)$ em $9 \mathrm{e}$ $11 / 5 / 2005$ utilizando-se um equipamento TDR modelo HydroSense fabricado pela Campbell Scientific Austrália Pty. Ltd.. Essa técnica permite a determinação da umidade do solo por meio da relação entre a umidade e a capacidade dielétrica de um solo mineral, conforme Equação 1 desenvolvida por Topp et al. (1980):

$$
\theta=-5,310^{-2}+2,9210^{-2} \varepsilon_{b}-5,510^{-4} \varepsilon_{b}^{2}+4,310^{-6} \varepsilon_{b}^{3}(1)
$$

em que q é a umidade do solo expresso em $\mathrm{m}^{3}$ $\mathrm{m}^{-3}$; e $\mathrm{e}_{b}$ é a constante dielétrica (adimensional) do meio poroso, que engloba sólidos, água e ar.

As amostragens realizadas em 10/1 (AAnel), 9/5 (A-TDR09) e 11/5/2005 (A-TDR11) correspondem a amostras simples de umidade sem repetições.

No dia $1 .^{\circ} / 2 / 2005$, a amostragem da umidade do solo foi realizada com três repetições sendo, a primeira a $2 \mathrm{~m}$ abaixo do ponto de amostragem (A-A); a segunda realizada exatamente no ponto de amostragem (U-B), e a terceira a $2 \mathrm{~m}$ acima do ponto de amostragem (U-C) (Figura 2). Esse tipo de amostragem com repetições permitiu a determinação do armazenamento médio de água pelo solo (A-M) e a obtenção do armazenamento de água para todos os pontos de amostragem, totalizando 906 pontos (A-906).

A amostragem do solo nas diferentes datas permitiu o cálculo do armazenamento de água no solo (mm), conforme descrito por ReICHARDT e TIMM (2004). Posteriormente, foi avaliada a perda média diária de água pelo solo entre as datas de monitoramento da umidade. O primeiro período de estudo compreende os vinte e dois dias entre as amostragens realizadas no dia 10/1 e 1. \% /2/2005 (PA, P-B, P-C, P-M e P-906), e o segundo período de estudo de dois dias está compreendido entre $9 / 5$ e 11/5/2005 (P-TDR). A perda média diária de água $\left(\mathrm{mm} \mathrm{dia}^{-1}\right)$ pelo solo foi determinada de acordo com Reichardt e Timm (2004), possibilitando então, quantificar a quantidade de água perdida pelo solo no período de estudo (Equação 2):

$$
P M D=\frac{A_{f}-A_{i}}{t}
$$

Em que: $P M D$ - perda média diária de água pelo solo em $\mathrm{mm} \mathrm{dia}{ }^{-1} ; A_{f}$ - armazenamento de água final em $\mathrm{mm} ; A_{i}-$ armazenamento de água inicial $\mathrm{mm}$ e $t$ - tempo em dias. 
A ocorrência de chuvas sobre a área de estudo (Figura 3) foi monitorada por meio de pluviômetro (Modelo Paulista) instalado ao lado da área de estudo. Os valores diários de radiação solar $\left(\mathrm{MJ} \mathrm{m}^{2} \mathrm{dia}^{-1}\right)$ (Figura 4) e temperatura máxima $\left({ }^{\circ} \mathrm{C}\right)$ (Figura 4) e direção predominante do vento (Figura 5) foram coletados na Estação Meteorológica Automática (EMA) do Centro de Ecofisiologia e Biofísica (IAC), localizada a cerca de $600 \mathrm{~m}$ da área de estudo.

Os dados foram analisados por meio da estatística descritiva utilizando software BIOESTAT 3.0 (AYREs et al., 2003), que forneceu os principais momentos estatísticos (média, mediana, variância, desvio-padrão, coeficiente de variação, valor mínimo, valor máximo, assimetria, curtose e o desvio máximo em relação à distribuição normal por meio do teste de Kolmogorov-Smirnov). Ferramentas de geoestatística foram utilizadas para avaliar a variabilidade espacial dos dados e a construção de mapas de isolinhas. Semivariogramas experimentais foram construídos para se determinar a variabilidade e dependência espacial entre as amostras, por meio do software GEOESTAT (VIEIRA et al., 2002).

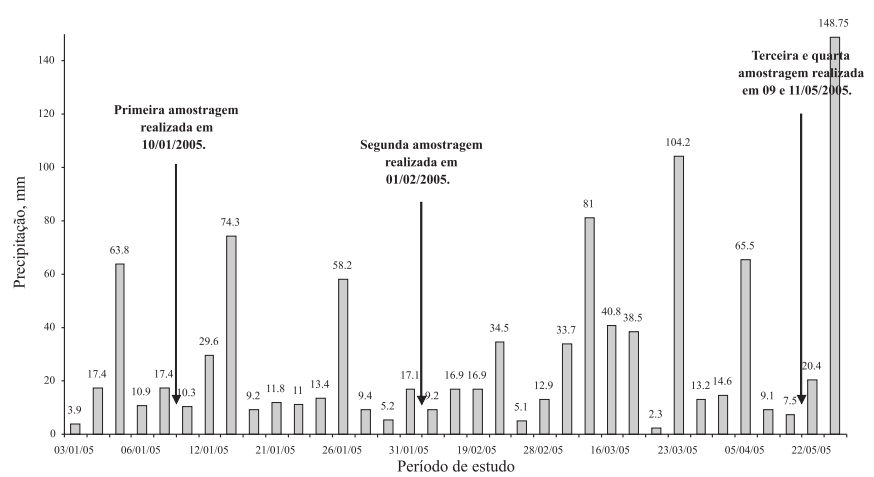

Figura 3. Precipitação pluvial diária sobre a área de estudo de janeiro a maio de 2005.

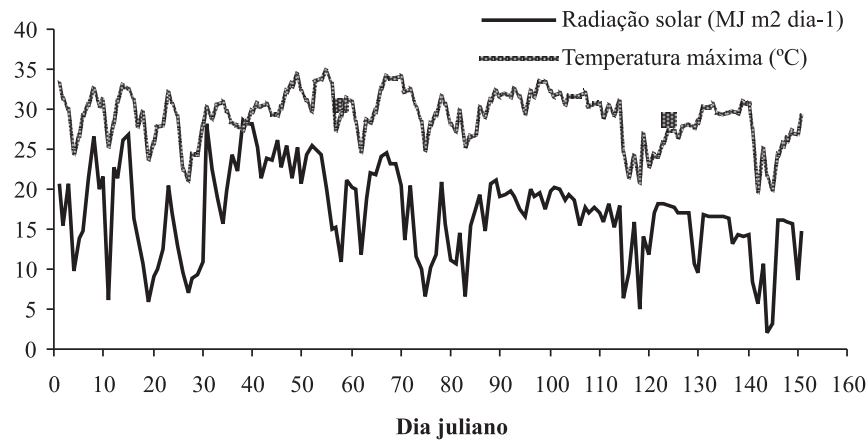

Figura 4. Valores de radiação solar $\left(\mathrm{MJ} \mathrm{m}^{2} \mathrm{dia}^{-1}\right)$ e de temperatura máxima $\left({ }^{\circ} \mathrm{C}\right)$ para os 151 dias julianos envolvidos no estudo (janeiro a maio de 2005).

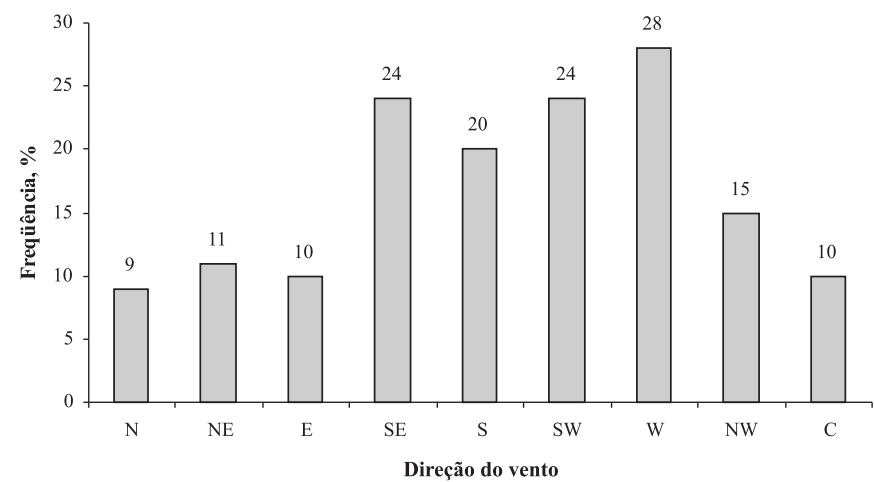

Figura 5. Freqüência de direção do vento no período de janeiro a maio de 2005.

Os semivariogramas com dependência espacial foram ajustados com o modelo matemático esférico e validados por meio da validação cruzada (Vieira, 2000). Desta maneira, foi possível a determinação dos parâmetros de ajuste do semivariograma: efeito pepita $\left(\mathrm{C}_{0}\right)$; variância estrutural $\left(C_{1}\right)$; patamar $\left(C_{0}+C_{1}\right)$ e alcance (a). Uma vez ajustado um modelo matemático ao semivariograma, foi determinada a razão de dependência espacial (RD) que representa a porcentagem de efeito pepita $\left(C_{0}\right)$ em relação ao patamar $\left(\mathrm{C}_{0}+\mathrm{C}_{1}\right)$, conforme proposto por Cambardella et al. (1994) (Equação 3): < 25\% dependência forte; de $25 \%$ a $75 \%$ - dependência moderada e $>75 \%$ - dependência fraca.

$$
R D=\left(\frac{C_{0}}{C_{0}+C_{1}}\right) \cdot 100
$$

A técnica de krigagem foi utilizada, para avaliação dos valores nos locais não amostrados por ser um estimador linear não enviesado. Uma vez determinados os valores para os locais não amostrados com a ajuda da técnica de krigagem, foram construídos mapas de isolinhas utilizando-se o programa SURFER (1999), que utiliza os mesmos valores estimados por meio da técnica de krigagem para determinação e localização das isolinhas; desta maneira, os mapas representam linhas bem definidas e embasadas em um algoritmo de regressão linear, conforme descrito por CARVALHO e AsSad (2005).

\section{RESULTADOS E DISCUSSÃO}

$\mathrm{Na}$ tabela 1, verificam-se os principais parâmetros estatísticos do armazenamento de água (A-Anel, A-A, A-B, A-C, A-M, A-906, A-TDR09 e ATDR11) e da perda média diária de água (P-A, P-B, P-C, P-M, P-906 e P-TDR). Gomes (1976) classifica o coeficiente de variação como baixo $(<10 \%)$, médio 
(10\%-20\%), alto (20\%-30\%) e muito alto (> 30\%); desta maneira, a maioria dos dados para o armazenamento de água em cada uma das datas de amostragem indica coeficiente de variação entre médio e alto. Os dados de perda média diária de água representam valores de coeficiente de variação muito alto. Esse fato pode ser explicado considerando o grande número de operações matemáticas necessárias para sua obtenção e pela grande instabilidade deste parâmetro no espaço e no tempo.

Tabela 1. Parâmetros estatísticos para o armazenamento de água obtido por diferentes métodos de avaliação da umidade do solo e pela diferença entre períodos de amostragem, na camada de 0,0 - 0,10 $\mathrm{m}$

\begin{tabular}{lccccccccccc}
\hline Atributo & Unidade & Média & Mediana & Variância & DP & $\begin{array}{r}\text { CV } \\
\%\end{array}$ & Mínimo & Maximo & Assimetria & Curtose & D \\
\hline A-Anel & $\mathrm{mm}$ & 41,505 & 41,42 & 26,970 & 5,19 & 12,51 & 27,59 & 60,52 & 0,256 & 0,700 & $0,034 \mathrm{n}$ \\
A-A & $\mathrm{mm}$ & 36,900 & 35,33 & 52,823 & 7,26 & 19,70 & 20 & 77 & 2,009 & 6,721 & $0,184 \mathrm{Ln}$ \\
A-B & $\mathrm{mm}$ & 36,016 & 34,29 & 90,746 & 9,52 & 26,45 & 17 & 80 & 1,371 & 3,242 & $0,149 \mathrm{Ln}$ \\
A-C & $\mathrm{mm}$ & 36,314 & 35,21 & 77,424 & 8,79 & 24,23 & 11 & 85 & 1,784 & 6,775 & $0,209 \mathrm{Ln}$ \\
A-M & $\mathrm{mm}$ & 36,440 & 34,97 & 38,620 & 6,21 & 17,05 & 24 & 66 & 1,710 & 4,850 & $0,141 \mathrm{Ln}$ \\
A-906 & $\mathrm{mm}$ & 36,412 & 35,01 & 73,550 & 8,57 & 23,55 & 11 & 85 & 1,636 & 5,288 & $0,174 \mathrm{Ln}$ \\
A-TDR09 & $\mathrm{mm}$ & 12,102 & 12,00 & 4,657 & 2,15 & 17,83 & 7 & 21 & 0,461 & 0,761 & $0,138 \mathrm{Ln}$ \\
A-TDR11 & $\mathrm{mm}$ & 11,457 & 11,00 & 5,657 & 2,37 & 20,76 & 7 & 20 & 0,893 & 1,293 & $0,155 \mathrm{Ln}$ \\
P-A & $\mathrm{mm} \mathrm{dia}^{-1}$ & $-0,181$ & $-0,35$ & 0,390 & 0,55 & $-305,52$ & $-1,419$ & 6,037 & 5,036 & 52,042 & $*$ \\
P-B & $\mathrm{mm} \mathrm{dia}^{-1}$ & $-0,223$ & $-0,40$ & 0,369 & 0,60 & $-271,89$ & $-1,346$ & 5,505 & 3,366 & 26,442 & $*$ \\
P-C & $\mathrm{mm} \mathrm{dia}^{-1}$ & $-0,214$ & $-0,38$ & 0,362 & 0,60 & $-280,20$ & $-1,549$ & 6,190 & 4,607 & 43,331 & $*$ \\
P-M & $\mathrm{mm} \mathrm{dia}^{-1}$ & $-0,233$ & $-0,33$ & 0,154 & 0,39 & $-168,44$ & $-1,453$ & 1,101 & 0,577 & 1,987 & $*$ \\
P-906 & $\mathrm{mm} \mathrm{dia}^{-1}$ & $-0,206$ & $-0,37$ & 0,346 & 0,58 & $-284,73$ & $-1,549$ & 6,190 & 4,260 & 39,075 & $*$ \\
P-TDR & $\mathrm{mm} \mathrm{dia}^{-1}$ & $-0,322$ & $-0,47$ & 1,892 & 1,37 & $-426,16$ & -4 & 4 & 0,323 & 0,298 & $*$ \\
\hline
\end{tabular}

DP: Desvio-padrão. CV: Coeficiente de variação. D: Desvio máximo em relação à distribuição normal. n: Dados que apresentam distribuição normal. Ln: Dados que apresentam distribuição Lognormal (probabilidade de erro de $5 \%$ pelo teste de Kolmogorov-Smirnov). ${ }^{*}$ não foi possível verificar o desvio máximo em relação à distribuição normal, uma vez que o conjunto de dados indica valores negativos.

Verifica-se que apenas no armazenamento de água coletado em 10/1/2005 (A-Anel) a distribuição foi normal para o conjunto de dados, conforme constatado pelo teste de normalidade de Kolmogorov-Smirnov com probabilidade de erro de $5 \%$. Os valores de média e mediana para os dados de armazenamento de água estão bem próximos, porém, quando analisamos conjuntamente os valores de assimetria e curtose, verificam-se, para a grande maioria dos dados, valores diferentes e distanciados de zero. IsaAKs e SRIVAstava (1989) descrevem que o coeficiente de assimetria é mais sensível à presença de valores extremos, quando comparado com média, mediana e desvio padrão, e neste caso um único valor extremo pode comprometer os resultados do coeficiente de assimetria, pois os desvios entre cada valor e a média são elevados à terceira potência. Assim, analisando o valor mínimo, o valor máximo e a variância dos dados, confirma-se que apenas em AAnel a distribuição foi normal e em A-TDR09 e A-TDR11 havia tendência para distribuição normal dos dados. Para a perda média diária de água pelo solo verifica-se que os valores de assimetria e curtose são consideravelmente elevados. Percebe-se também que os valores da média não estão próximos um dos outros, indicando distribuição não normal para os dados.

Os valores negativos de média para os dados de perda média diária de água pelo solo nos períodos de estudo indicam locais onde houve maior armazenamento de água em algumas regiões da área (Equação 2). Comparando os valores de desvio-padrão (DP) e de coeficiente de variação $(\mathrm{CV})$, pode-se ter uma idéia sobre a amplitude dos dados e, desta maneira, percebe-se que as maiores diferenças são relatadas para a perda média diária de água pelo solo. Este fato pode ser comprovado pelos valores mínimo e máximo para o conjunto de dados.

Na tabela 2, verificam-se os valores de ajuste do semivariograma para todos os atributos estudados. $\mathrm{O}$ modelo esférico se ajustou a todos os dados dos atributos analisados, com exceção de P-B, cujo efeito pepita puro, ou seja, o espaçamento entre amostras não foi suficiente para detectar a dependência espacial entre as amostras da perda média diária de água. No geral, o armazenamento de água e a perda média diária de água pelo solo representam a razão de dependência espacial entre amostras com tendência moderada fraca, conforme classificação proposta por CAMBARdella et al. (1994). 
O maior valor de razão de dependência espacial foi descrito para P-TDR (99,98\%), e pode ser justificado em função da grande demanda da cultura da mamona e da atmosfera por água neste período, em que ocorrem poucas precipitações pluviais. Esse fato faz com que cada uma das amostras que compõem este atributo exerça pouca influência entre seus vizinhos, pois a quantidade de água presente nesta camada do solo $(0,0-0,1 \mathrm{~m})$ é relativamente pequena.

Tabela 2. Parâmetros do semivariograma para os atributos analisados

\begin{tabular}{|c|c|c|c|c|c|c|c|c|}
\hline Atributo & Unidade & Modelo & $\mathrm{C}_{0}$ & $\mathrm{C}_{1}$ & $\begin{array}{c}\mathrm{a} \\
\mathrm{m}\end{array}$ & $\mathrm{R}^{2}$ & SQDP & $\begin{array}{c}\text { RD } \\
\%\end{array}$ \\
\hline A-Anel & $\mathrm{mm}$ & Esférico & 12,500 & 4,400 & 56,00 & 0,539 & 0,406 & 73,96 \\
\hline $\mathrm{A}-\mathrm{A}$ & $\mathrm{mm}$ & Esférico & 46,000 & 13,700 & 44,00 & 0,295 & 5,535 & 77,05 \\
\hline A-B & $\mathrm{mm}$ & Esférico & 70,000 & 20,000 & 35,00 & 0,085 & 20,620 & 77,78 \\
\hline$A-C$ & $\mathrm{~mm}$ & Esférico & 65,000 & 20,000 & 40,00 & 0,246 & 20,650 & 76,47 \\
\hline A-M & $\mathrm{mm}$ & Esférico & 26,000 & 16,000 & 40,00 & 0,432 & 5,347 & 61,90 \\
\hline A-906 & $\mathrm{mm}$ & Esférico & 48,000 & 32,000 & 39,00 & 0,670 & 0,155 & 60,00 \\
\hline A-TDR09 & $\mathrm{mm}$ & Esférico & 2,400 & 1,930 & 28,00 & 0,487 & 0,020 & 55,43 \\
\hline A-TDR11 & $\mathrm{mm}$ & Esférico & 3,400 & 2,000 & 35,00 & 0,459 & 0,049 & 62,96 \\
\hline P-A & $\mathrm{mm} \mathrm{dia}^{-1}$ & Esférico & 0,215 & 0,056 & 40,00 & 0,169 & $1 \times 10-4$ & 79,34 \\
\hline P-B & $\mathrm{mm} \mathrm{dia}^{-1}$ & * & * & * & * & * & * & * \\
\hline P-C & $m m \operatorname{dia}^{-1}$ & Esférico & 0,280 & 0,060 & 41,00 & 0,204 & $1 \times 10^{-4}$ & 82,35 \\
\hline P-M & $\mathrm{mm} \mathrm{dia}{ }^{-1}$ & Esférico & 0,089 & 0,030 & 22,00 & 0,061 & $2 \times 10^{-5}$ & 74,79 \\
\hline P-906 & $\mathrm{mm} \mathrm{dia}{ }^{-1}$ & Esférico & 0,103 & 0,087 & 22,00 & 0,928 & $1 \times 10^{-5}$ & 54,21 \\
\hline P-TDR & $\mathrm{mm} \mathrm{dia}^{-1}$ & Esférico & 1,710 & 0,400 & 26,00 & 0,116 & 0,009 & 99,98 \\
\hline
\end{tabular}

$\mathrm{C}_{0}$ : Efeito pepita. $\mathrm{C}_{1}$ : Variância estrutural. a: Alcance. $\mathrm{R}^{2}$ : Coeficiente de correlação. SQDP: Soma de quadrados de desvios ponderados. RD: Razão de dependência espacial.

De acordo com CarvalHo et al. (2001), o efeito pepita $\left(\mathrm{C}_{0}\right)$ indica a descontinuidade entre as amostras. Assim, os maiores valores de descontinuidade entre amostras foram constatados entre as amostras coletadas em 1. $\%$ 2/2005 (A-A, A-B, A-C, A-M e A-906). O menor valor de alcance (a) foi constatado para P-M e P-906 (22 metros). Este fato sugere que a grade de amostragem pode ser ampliada para uma distância maior, diminuindo os custos com o monitoramento da armazenagem de água no solo. Desta maneira o alcance fornece uma medida do tamanho médio das manchas de variabilidade espacial.

$\mathrm{O}$ armazenamento de água varia em função da quantidade de água que entra no perfil do solo e dos fatores que contribuem para que permaneça armazenada (PAZ GonZÁlez e Alves, 2005). As figuras 6 e 7 representam, respectivamente, os mapas de isolinhas do armazenamento $(\mathrm{mm})$ e da perda média diária de água pelo solo $\left(\mathrm{mm} \mathrm{dia}^{-1}\right)$.

Como a camada de estudo é superficial $(0,0$ $0,1 \mathrm{~m})$, é possível dizer que a quantidade de água armazenada nesta camada é reflexo direto da água consumida pelas plantas, e da taxa de evaporação que depende da energia disponível para esse processo e dos elementos meteorológicos, conforme demonstrado por Ramírez e López (1993). Pela análise dos mapas de isolinhas do armazenamento de água (Figura 6), constata-se que os maiores valores de armazenamento estão localizados na parte superior direita da área, com exceção de 10/1/2005, quando ocorreram os maiores valores de armazenagem de água na parte esquerda da área. Verifica-se também que o armazenamento de água em 9 e 11/5/2005 revelam diferenças significativas, indicando grande perda de água para a atmosfera no período de dois dias que separa as duas amostragens.

Os valores dos momentos estatísticos (Tabela 1), dos parâmetros geoestatísticos (Tabela 2) e dos mapas de isolinhas para o armazenamento de água (Figura 6) e para a perda média diária de água (Figura 7) indicam estabilidade temporal para os dados. Esse fato pode ser explicado por VAUCHAUD et al. (1985) que ressaltam a existência de alta probabilidade de uma posição mais úmida em determinado instante permanecer assim em outros momentos, devido à perda de água para a atmosfera ser controlada pela demanda evaporativa do ambiente. Este fato se deve, principalmente porque em locais com maiores quantidades de água no solo sempre houve maiores quantidades de água do que naqueles onde a quantidade de água no solo é menor. É importante realizar uma análise conjunta dos parâmetros de ajuste do semivariograma e dos mapas de isolinhas, conforme descrito por GREGO e VIEIRA (2005), para identificar a variabilidade dos dados e a presença de regiões com maior conteúdo de água no solo ou locais com maiores perdas para as plantas e atmosfera. VAUCHAUD et al. (1985) concluíram ainda que a armazenagem de água em determinado local é resultado de uma série de processos hidrológicos que operam em diferentes escalas espaciais. 


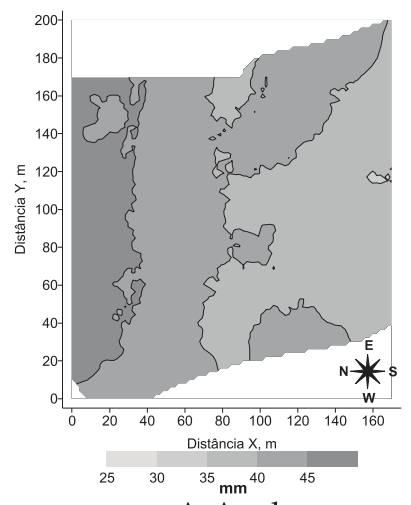

A-Anel
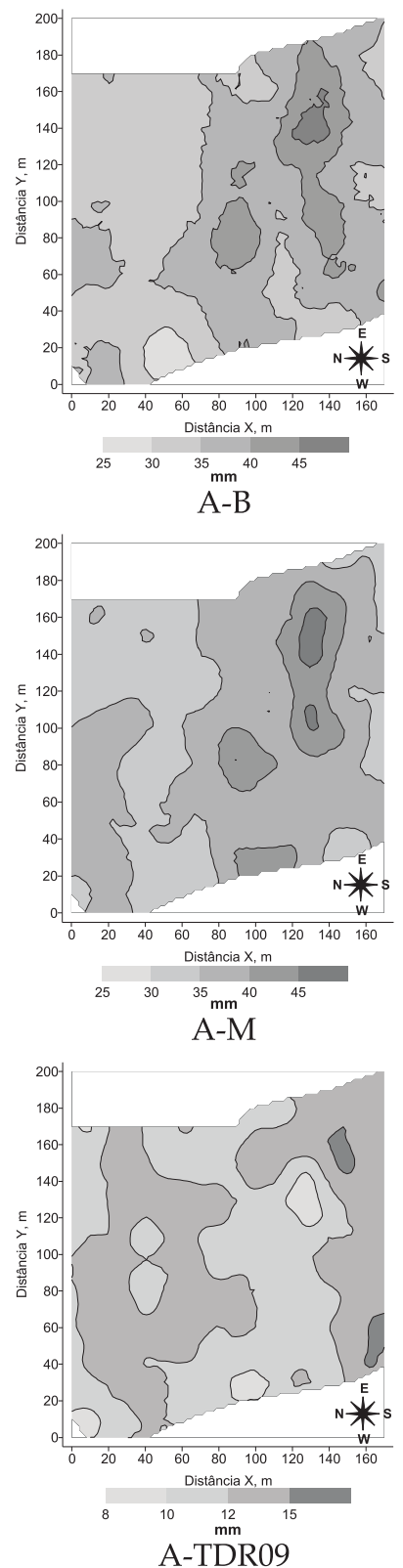

Figura 6. Mapas de isolinhas para o armazenamento de água no solo (mm) em 10/1/2005 (A-Anel), 1. /2/2005 (A-A, A-B, A-C, A-M e A-906), 9/5/2005 (A-TDR09) e 11/5/2005 (A-TDR11).
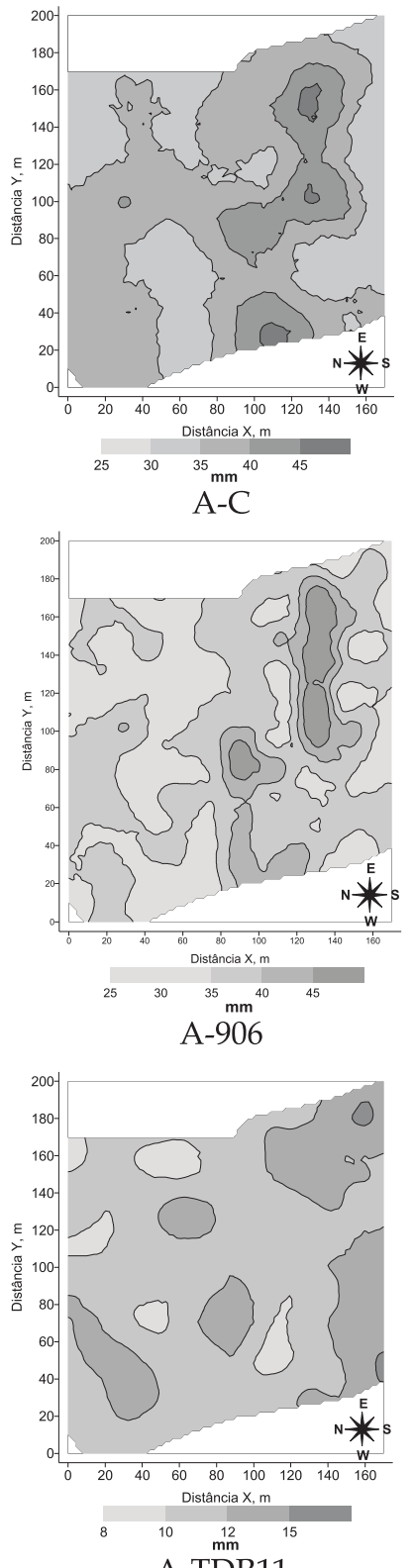
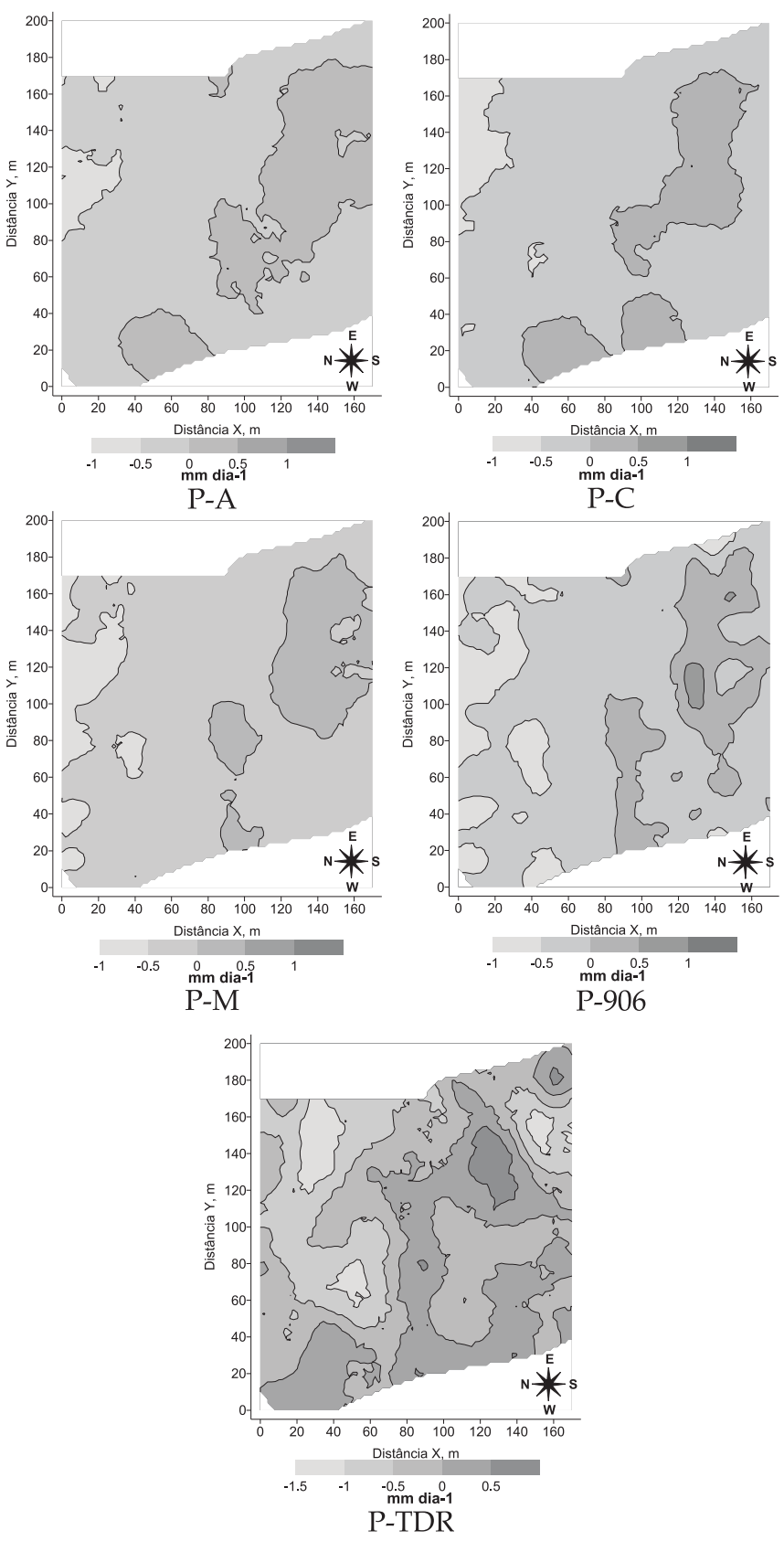

Figura 7. Mapas de isolinhas para a perda média diária de água $\left(\mathrm{mm} \mathrm{dia}^{-1}\right)$ no primeiro (P-A, P-B, P-C, P-M e $\mathrm{P}-906)$ e no segundo período de estudo (P-TDR).

Todavia, AHujA et al. (1993) descrevem como as mudanças ao longo tempo do conteúdo de água no solo interferem na manifestação da variabilidade espacial. Esse fato pode ser constatado por meio das diferenças entre os parâmetros de ajuste do semivariograma para o armazenamento de água no solo e para a perda média diária de água pelo solo. No entanto, nos mapas de variabilidade espacial, nota-se determinado padrão de similaridade entre as diferentes datas de amostragem do armazenamento de água e para os dois períodos de estudo da perda média diária de água pelo solo. 
Percebe-se, também, que os valores de efeito pepita $\left(C_{1}\right)$ variam entre os atributos envolvidos neste estudo (Tabela 2); este fato já era esperado em função da variabilidade não detectada pelo processo de amostragem. Todavia, o tamanho das manchas de variabilidade espacial expresso pelo alcance (a) para o armazenamento de água está em torno dos $40 \mathrm{~m}$ e para a perda média diária de água em torno dos 22 metros. Os valores de razão de dependência espacial (RD) também apresentam determinada relação entre os atributos envolvidos no presente estudo. Este fato é mais evidenciado nos dados do armazenamento de água no solo do que nos dados da perda média diária de água pelo solo.

A análise dos mapas de variabilidade espacial do armazenamento de água e da perda média diária de água pelo solo demonstra que os locais mais úmidos sempre permaneceram mais úmidos nas diferentes datas de amostragem e que aqueles com maiores perdas de água para o sistema seguem o mesmo padrão espacial.

Dentre as características relacionadas com o histórico da área, a mais importante talvez seja com relação ao sistema de manejo praticado. Sabe-se que no sistema de semeadura direta a palha em superfície diminui o escorrimento superficial e propicia maior quantidade de água infiltrada no perfil, diminuindo as perdas por evaporação e contribuindo para o aumento da umidade do solo tanto em superfície quanto em camadas mais profundas (TAVARES FILHO et al., 2001; Camara e Klein, 2005; Silva et al., 2006). Por outro lado, o dossel das culturas e a palha mantida na superfície do solo no sistema de semeadura direta favorecem o desenvolvimento de um microclima característico (Weirich Neto et al., 2002; Rosolem et al., 2003), contribuindo para a manutenção da água no solo (TAvares Filho et al., 2001; Camara e Klein, 2005).

Verifica-se, na área de estudo, que os menores valores de armazenamento de água (Figura 6) e os maiores valores de perda média diária de água (Figura 7) para a atmosfera estão relacionados com a face norte do terreno, fato também relatado por ORTIZ (2003). LOPEZ (1973), estudando terrenos com diferentes declividades e com faces de exposição norte $(\mathrm{N})$ e sul $(\mathrm{S})$, observou que a face norte $(\mathrm{N})$ recebeu maior quantidade de radiação incidente, refletindo na temperatura e na quantidade de água no solo. Esse fato também é descrito por Oliveira (2005), ao relatar que o maior armazenamento de água é função dos menores valores de evapotranspiração.

Relacionando-se o conteúdo de água no solo e as datas de coleta, pode-se dizer que: a amostragem da umidade do solo em 10/1/2005 (A-Anel) foi realizada após um período intenso de chuvas (Figura 3) tendo acumulado até $8 / 1 / 2005$, aproximadamente, $288 \mathrm{~mm}$, responsável pelos $45 \mathrm{~mm}$ de armazenamento de água em algumas partes da área. $A$ amostragem realizada em 1. $\%$ 2/2005 (A-A, A-B, A-C, A-M e A-906) também recebe influência da precipitação pluvial anterior a essa data, uma vez que o volume de chuvas anterior à amostragem manteve-se constante com acumulado de $249 \mathrm{~mm}$, garantindo também armazenamento de água acima de $45 \mathrm{~mm}$ em algumas partes da área. As maiores diferenças entre os mapas de armazenamento de água para as amostragens realizadas em 10/1/2005 e 1.\% $2 / 2005$ são respostas diretas da precipitação no período de estudo, uma vez que no anterior, em 10/1/2005, as chuvas foram mais freqüentes e o volume precipitado foi mais bem distribuído nos dias anteriores à amostragem. Para a segunda data de amostragem, o volume de chuvas não foi bem distribuído no período assumindo um valor máximo de precipitação de $74 \mathrm{~mm}$ no dia 19/1/2005 e um mínimo de 5 mm em 30/1/2005. Daí as maiores diferenças entre os mapas de armazenamento de água para essas duas datas de amostragem do conteúdo de água no solo.

As duas amostragens de umidade do solo realizadas em 9 e 11/05/2005 foram realizadas após longo período de estiagem (Figura 3), cujo último dia de chuvas $(29 / 4 / 2005)$ anterior à amostragem realizada em 9/5/2005 foi de $7,5 \mathrm{~mm}$, ou seja, até a data da amostragem se passaram dez dias sem chuvas; daí, os menores valores de armazenamento de água para A-TDR09 e A-TDR11, confirmando os maiores valores de perda média diária de água pelo solo neste período (P-TDR).

Analisando os mapas de variabilidade espacial do armazenamento (Figura 6) e da perda média diária de água pelo solo (Figura 7), constatase como os valores de temperatura máxima do ar e de radiação solar incidente sobre a área (Figura 4) interferem sobre o conteúdo de água no solo para a camada estudada $(0,0-0,1 \mathrm{~m})$. Observa-se que nos dias que antecedem à primeira avaliação do armazenamento de água no solo, a radiação solar atinge em 8 de janeiro de 2005 ( $8 .^{\circ}$ dia Juliano) o valor de $29,67 \mathrm{MJ} \mathrm{m}^{2} \mathrm{dia}^{-1}$ (Figura 4). A temperatura máxima também possui comportamento semelhante neste período, atingindo também em 8/1/2005 o índice de $28^{\circ} \mathrm{C}$. No entanto, no mapa de variabilidade espacial para A-Anel, observam-se as linhas de contorno com tendência preferencial na vertical com maior armazenamento de água na parte esquerda da área (face sul do terreno). Esse fato pode ser justificado pela presença de um cultivo com seringueira [Hevea brasilensis (Willd. ex Adr. de Juss.) Muell-Arg.] com árvores com cerca de $6 \mathrm{~m}$ de altura na parte esquerda da área. Neste caso, o seringal interferiu sobre a ação do vento nesta parte da área, pois no período anterior 
a esta amostragem o vento soprou predominantemente na direção norte $(\mathrm{N})$.

Para o dia $1 .^{\circ}$ de fevereiro de 2005, o maior valor de radiação solar antes da data de amostragem é relatado para 31/1/2005 (31. ${ }^{\circ}$ dia Juliano do ano) com cerca de $28 \mathrm{MJ} \mathrm{m}^{2} \mathrm{dia}^{-1}$ e com temperatura máxima neste dia em torno dos $30{ }^{\circ} \mathrm{C}$. No período antecessor a esta data de amostragem o vento soprava principalmente da direção sul (S). Assim, o seringal por sua vez favorecia a formação de turbilhões. De acordo com DURIGAN (1986), os quebra-ventos, pouco porosos, são muito eficientes na redução da velocidade do vento junto à barreira, mas a proteção se estende por uma distância relativamente curta. Assim, a proteção oferecida pelo seringal não se mantém por toda a área, sendo garantida apenas para os ventos provenientes da direção norte $(\mathrm{N})$, e em uma pequena faixa da área. Desta maneira, como o vento que atinge a área de estudo possui a direção sul (S) como predominante, há constante formação de turbilhões na parte esquerda da área favorecendo maiores perdas por evapotranspiração nesta parte da área.

Em 9 e 11 de maio de $2005\left(128 .^{\circ}\right.$ e $1300^{\circ}$ dia Juliano), a radiação solar incidente sobre a área atinge valores de $16 \mathrm{MJ} \mathrm{m}^{2} \mathrm{dia}^{-1}$ e $9 \mathrm{MJ} \mathrm{m}^{2} \mathrm{dia}^{-1}$ (Figura 4), nos dias anteriores às duas amostragens. A temperatura máxima assumiu o índice próximo de $28^{\circ} \mathrm{C}$ (Figura 4). Nesse período, o vento soprou para quase todas as direções não havendo direção predominante. Contudo, conforme já discutido, a maior contribuição para os valores de armazenamento de água (Figura 6) e de perda média diária de água (Figura 7) pelo solo se deve à longa estiagem nesse período.

O vento que atinge a área de estudo atua principalmente na direção sudeste, conforme constatado por BARBANO et al. (2003). Na figura 5, notase que, para o período de estudo, o vento atingiu a área de estudo principalmente vindo da direção sul (S), com 24 ocorrências para a direção sudeste (SE); 20 ocorrências para a direção sul (S) e 24 ocorrências na direção sudoeste (SW). Desta maneira, é possível dizer que o vento sopra sobre a área de estudo partindo principalmente do lado direito para o lado esquerdo. Assim, o vento sul (S) passa sobre a área e atinge o seringal que, por sua vez, provoca a formação de turbilhões que tendem a produzir correntes de ar no sentido oposto à barreira. Este fato pode explicar a presença de menores valores de armazenamento de água e maiores valores de perda média diária de água no lado esquerdo da área.

Por outro lado, é preciso considerar a ação atenuante da palha mantida na superfície do solo, no sistema de semeadura direta, contra a ação direta dos elementos meteorológicos. Segundo TAVARES FILHO et al. (2001) e Rosolem et al. (2003), o sistema de semeadura direta possui maior armazenamento de água quando comparado ao cultivo convencional. Assim, o armazenamento de água e a perda média de água pelo solo foram favorecidos pela palhada mantida na superfície do solo.

A variabilidade, tanto espacial quanto temporal da disponibilidade hídrica dos solos e sua interação com os fatores climáticos, é de suma importância para a quantificação das necessidades hídricas dos vegetais (AlFONSI et al., 1998), tendo em vista o manejo sustentável do solo e da água. Contudo é preciso considerar que a interação dos elementos meteorológicos pode variar entre espécies e cultivares, de uma mesma planta, dependendo de seu estádio de desenvolvimento, corroborando para a necessidade de mais estudos sobre a interação solo-planta-atmosfera.

\section{CONCLUSÕES}

1. O armazenamento de água no solo e a perda média diária de água pelo solo indicam similaridade no padrão de variabilidade espacial dos dados para a área de estudo.

2. Na face norte do terreno, ocorreram os menores valores de armazenamento de água no solo e de perda média diária de água pelo solo para a área nos diferentes períodos envolvidos neste estudo.

3. Não foi possível determinar a magnitude da interferência dos elementos meteorológicos sobre o armazenamento de água no solo para o período de estudo.

\section{AGRADECIMENTOS}

À Fundação de Apoio à Pesquisa Agrícola (FUNDAG) pela concessão de bolsa de mestrado para o primeiro autor e pelo financiamento parcial deste trabalho. Ao Ministério de Educação e Ciência da Espanha (Projeto CGL2005-08219-C02-02), a Xunta de Galícia (Projeto PGIDIT06PXIC291062PN) e ao Fundo Europeu de Desenvolvimento Regional (FEDER) pelo financiamento parcial deste trabalho. Ao Centro de Ecofisiologia e Biofísica do Instituto Agronômico pelo fornecimento dos dados meteorológicos.

\section{REFERÊNCIAS}

AHUJA, L.R.; WENDROTH, O.; NIELSEN, D.R. Relationship between initial drainage of surface soil and average profile saturated conductivity. Soil Science Society of America Journal, Madison, v.57, p.19-25, 1993. 
ALFONSI, R.R.; BRUNINI, O.; CAMARGO, M.B.P.; PEZZOPANE, J.R.M. Disponibilidade hídrica no solo para a cultura do milho no Estado de São Paulo, em função de épocas de semeadura e cultivares. Bragantia, Campinas, v.1, n.1, p.127133, 1998.

AYRES, M.; AYRES JUNIOR, M.; AYRES, D.L.; SANTOS, A.S. BioEstat 3.0: aplicações estatísticas nas áreas das ciências biológicas e médicas. Belém: Sociedade Civil Mamirauá; Brasília: CNPq, 2003. 290p.

BARBANO, M.T.; BRUNINI, O.; PINTO, H.S. Direção predominante do vento para a localidade de Campinas-SP. Revista Brasileira de Agroclimatologia, Santa Maria, v.11, n.1, p.123-128, 2003.

CAMARA, R.K.; KLEIN, V.A. Escarificação em plantio direto como técnica de conservação do solo e da água. Revista Brasileira de Ciência do Solo, v.29, n.5, p. 789-796, 2005.

CAMARGO, O.A., MONIZ, A.C; JORGE, J.A.; VALADARES, J.M.A.S. Métodos de análise química, mineralógica e física de solos do Instituto Agronômico de Campinas. Campinas: Instituto Agronômico, 1986. 94p. (Boletim Técnico, 106)

CAMBARDELLA, C.A.; MOOMAN, T.B.; NOVAK, J.M.; PARKIN, T.B.; KARLEN, D.L.; TURV, R.F.; KONOPA, A.E. Field scale variability of soil properties in central Iowa soil. Soil Science of Society America Journal, Madison, v.47, p.15011511, 1994.

CARVALHO, J.R.; ASSAD, E.D. Análise espacial da precipitação pluviométrica no Estado de São Paulo: comparação de métodos de interpolação. Engenharia Agrícola, Jaboticabal, v.25, n.2, p.377-384, 2005.

CARVALHO, J.R.; VIEIRA, S.R.; MARINHO, P.R.; DECHEN, S.C.F.; MARIA, I.C.; POTT, C.A.; DUFRANC, G. Avaliação da variabilidade espacial de parâmetros físicos do solo sob semeadura direta em São Paulo, Brasil. Campinas: EMBRAPA, 2001, p.1-4. (Comunicado Técnico)

DURIGAN, G. Efeito dos quebra-ventos de Grevillea robusta A. CUNN. sobre a velocidade do vento. $1986.74 f$. Dissertação (Mestrado) - ESALQ/USP, Piracicaba.

GREGO, C.R.; VIEIRA, S.R. Variabilidade espacial de propiedades físicas do solo em uma parcela experimental. Revista Brasileira de Ciência do Solo, Viçosa, v.29, p.169177, 2005.

GOMES, F.P. Curso de estatística experimental. 6.ed. Piracicaba: Binetti, 1976. 430p.

GONÇALVES, A.C.A.; FOLEGATTI, M.V.; VIEIRA, S.R. Padrões de amostragem e intensidade de krigagem na caracterização do armazenamento de água no solo, em área irrigada por pivô central. Revista Brasileira de Ciência do Solo, Viçosa, v.23, n.3, p.485-495, 1999.

ISAAKS, E.H.; SRIVASTAVA, R.M. An introduction to applied geoestatistics. New York: Oxford University, 1989. 561p.
LOPES, R.L. Efeitos da exposição sobre o microclima da cultura de sorgo. 1973. 105f. Tese (Doutorado) - Faculdade de Ciências Agrárias e Veterinárias - UNESP, Jaboticabal.

OLIVEIRA, J.B. Pedologia aplicada. Piracicaba: FEALQ, 2005. 574p.

ORTIZ, J.L. Emprego do geoprocessamento no estudo da relação entre potencial produtivo de um povoamento de eucalipto e atributos do solo e do relevo. 2003. 205f. Dissertação (Mestrado em Recursos Florestais) - Escola Superior de Agricultura “Luiz de Queiroz, Universidade de São Paulo, Piracicaba.

ORTOLANI, A.A.; CAMARGO, M.B.P.; PEDRO JÜNIOR, M.J. Normais climatológicas dos postos meteorológicos do Instituto Agronômico: 1. Centro Experimental de Campinas. Campinas: Instituto Agronômico, 1995. 13p. (Boletim Técnico, 155)

PAZ GONZÁLEZ, A.; ALVES, M.C. Armazenamento de água e densidade do solo sob três condições de superfície, em um Cambissol gleico de Lugo, Espanha. Revista Brasileira de Engenharia Agrícola e Ambiental, Campina Grande, v.9, n.1, p.45-50, 2005.

RAMÍREZ, A.A.; LÓPEZ, R.G. El água em el Suelo. In: MAÑAS, F.M.S.O.; VALERO, J.A. Agronomia del Riego. Mundi-Prensa: Ediciones Madrid, 1993. p.19-69.

REICHARDT, K.; TIMM, L.C. Solo, planta e atmosfera: conceitos, processos e aplicações. Barueri: Manole, 2004. 478p.

ROSOLEM, C.A.; FOLONI, J.S.S.; OLIVEIRA, R.H. Dinâmica do nitrogênio no solo em razão da calagem e adubação nitrogenada, com palha na superfície. Pesquisa Agropecuária Brasileira, Brasília, v.38, n.2, p.301-309, 2003.

SILVA, P.R.F.; ARGENTA, G.; SANGOI, L. STRIEDER, M.L.; SILVA, A.A. Estratégias de manejo de coberturas de solo no inverno para cultivo do milho em sucessão no sistema semeadura direta. Ciência Rural, Santa Maria, v.36, n.3, p.10111020, 2006.

SURFER for windows. Realese 7.0. Contouring and 3D surface mapping for scientist's engineers: User's guide. New York: Golden Software, 1999. 619p.

TAVARES FILHO, J.; BARBOSA, G.M.C.; GUIMARÃES, M.F.; FONSECA, I.C.B. Resistência do solo à penetração e desenvolvimento do sistema radicular do milho (Zea mays) sob diferentes sistemas de manejo em um latossolo roxo. Revista Brasileira de Ciência do Solo, Viçosa, v. 25, n.3, p.725-730, 2001.

TOPP, G.C.; DAVIS, J.L.; ANNAN, A.P. Eletromagnetic determination of soil water content: measurements in coaxial transmission lines. Water Resources Research, Washington, v.16, p.574-582,1980.

VAUCHAUD, G., DE SILANE., P. BALABANIS, A., VAUCLIN, M. Temporal stability of spatially measured soil water probability density function. Soil Science of Society America Journal, Madison, v.49, p.822-7, 1985. 
VIEIRA, S.R.; DE MARIA, I.C.; LOMBARDI NETO, F.; DECHEN, S.C.F.; CASTRO, O.M. Caracterização da variabilidade espacial de propriedades físicas. Campinas: Instituto Agronômico, 1992. p.41-51. (Documentos IAC, 29)

VIEIRA, S.R. Geoestatística em estudos de variabilidade espacial do solo. In: NOVAIS, R.F., ALVAREZ, V.H., SCHAEFER, G.R. (Ed.). Tópicos em Ciência do Solo. Viçosa: Sociedade Brasileira de Ciência do Solo, 2000. v.1, p. 1-54.
VIEIRA, S.R.; MILLETE, J.; TOPP, G.C.; REYNOLDS, W.D. Handbook for geoestatistical analysis of variability in soil and climate data. In: ALVAREZ, V.V.H.; SCHAEFER, C.E.G.R.; BARROS, N.F.; MELLO, J.W.V.; COSTA, J.M. Tópicos em Ciência do Solo. Viçosa: Sociedade Brasileira de Ciência do Solo, 2002. v.2, p.1-45.

WEIRICH NETO, P.H., ROSA, A.L.T.; GOMES, J.A. Suscetibilidade de dois tipos de solo à compactação. Revista Brasileira de Engenharia Agrícola e Ambiental, Campina Grande, v.6, n.2, p.349-353, 2002. 